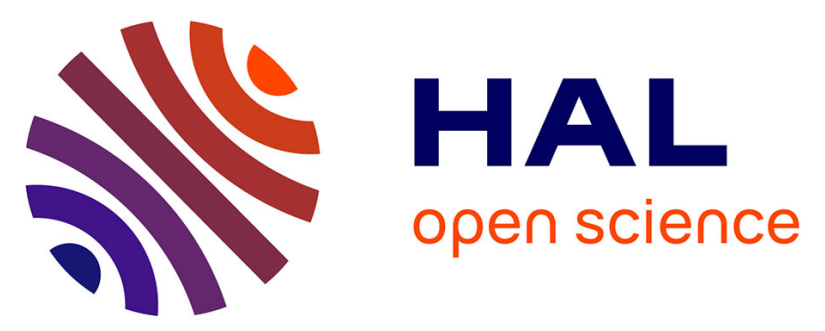

\title{
Performance simulation of different toolpaths in 2D1/2 pocket milling
}

Cédric Leroy, Edouard Rivière-Lorphèvre, Francois Ducobu, Sylvain Lavernhe, Christophe Tournier, Enrico Filippi

\section{To cite this version:}

Cédric Leroy, Edouard Rivière-Lorphèvre, Francois Ducobu, Sylvain Lavernhe, Christophe Tournier, et al.. Performance simulation of different toolpaths in 2D1/2 pocket milling. PROCEEDINGS OF THE 22ND INTERNATIONAL ESAFORM CONFERENCE ON MATERIAL FORMING: ESAFORM 2019, May 2019, Vitoria-Gasteiz, Spain. pp.080001, 10.1063/1.5112609 . hal-02571164

\section{HAL Id: hal-02571164 \\ https://hal.science/hal-02571164}

Submitted on 12 May 2020

HAL is a multi-disciplinary open access archive for the deposit and dissemination of scientific research documents, whether they are published or not. The documents may come from teaching and research institutions in France or abroad, or from public or private research centers.
L'archive ouverte pluridisciplinaire HAL, est destinée au dépôt et à la diffusion de documents scientifiques de niveau recherche, publiés ou non, émanant des établissements d'enseignement et de recherche français ou étrangers, des laboratoires publics ou privés. 


\section{Performance simulation of different toolpaths in 2D1/2 pocket milling}

Cite as: AIP Conference Proceedings 2113, 080001 (2019); https://doi.org/10.1063/1.5112609

Published Online: 02 July 2019

Cédric Leroy, Edouard Rivière-Lorphèvre, Francois Ducobu, Sylvain Lavernhe, Christoph Tournier, and Enrico Filippi

\section{ARTICLES YOU MAY BE INTERESTED IN}

Finite-element simulations of Al7075-T6 orthogonal cutting: Effect of part geometry and mesh on chip morphology and formation mechanism

AIP Conference Proceedings 2113, 080003 (2019); https://doi.org/10.1063/1.5112611

Importance of the contact interface definition in the numerical simulation of tool wear in metal cutting

AIP Conference Proceedings 2113, 080007 (2019); https://doi.org/10.1063/1.5112615

Comparison of Johnson-Cook and modified Johnson-Cook material constitutive models and their influence on finite element modelling of Ti6Al4V orthogonal cutting process

AIP Conference Proceedings 2113, 080009 (2019); https://doi.org/10.1063/1.5112617

\section{Lock-in Amplifiers up to $600 \mathrm{MHz}$

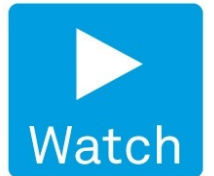

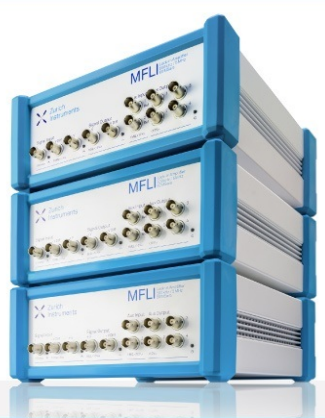




\title{
Performance Simulation of Different Toolpaths in 2D1/2 Pocket Milling
}

\author{
Cédric Leroy $^{1, \text { a) }}$, Edouard Rivière-Lorphèvre ${ }^{1, b)}$, Francois Ducobu ${ }^{1, c)}$, \\ Sylvain Lavernhe ${ }^{2, \text { d) }}$, Christoph Tournier ${ }^{2,}$ e), Enrico Filippi ${ }^{1, \text { f) }}$ \\ ${ }^{1}$ Machine Design and Production Lab - Faculty of Engineering - UMONS \\ Place du Parc, 20 - B-7000 MONS - BELGIUM \\ ${ }^{2}$ LURPA - ENS de CACHAN-avenue du Président Wilson, 61 - 94235 CACHAN. \\ a) cedric.leroy@umons.ac.be, ${ }^{\text {b) }}$ edouard.rivierelorphevre@umons.ac.be, ${ }^{\mathrm{c}}$ francois.ducobu@umons.ac.be, \\ d) sylvain.lavernhe@lurpa.ens-cachan.fr, ${ }^{\text {e) }}$ christophe.tournier@lurpa.ens-cachan.fr, \\ f) enrico.filippi@umons.ac.be
}

\begin{abstract}
Pocket milling is a common task in manufacturing of aeronautical or space use parts, but also for molds and dies. This process is time-consuming and has an important impact on the cost of the final product.

For this paper, among all the possible directions of 2D1/2 pocketing improvement, the optimization of toolpath geometry has been chosen. Most of time, the toolpaths are computed from a Computer Aided Manufacturing software using classical tool trajectories such as "zig-zag" or "contour parallel". These trajectories show discontinuities or local high curvature, creating frequent stop and go of the tool. These toolpaths are, fundamentally, not efficient in High Speed Milling. Some authors and software designers proposed methods to tackle those problems by local modification of the toolpath to improve his higher order continuity. Others, like M. Bieterman, build directly a C2 spiral tool path with low curvature (this strategy propose to solve numerically a 2D Partial Differential Equation problem and to use the iso-curves as structure curves to build the spiral). These strategies are efficient for High Speed Milling but leads to much longer toolpaths, so it can't be necessarily a beneficial way.

The goal of this paper is to compare, for 2D1/2 pocket roughing, the time performance of different machining strategies: "zig-zag", "contour parallel", morph spiral and "Bieterman" used on different homothetic rectangular pockets. For this purpose, VPOp software developed in the LURPA Lab from Cachan is used. With this procedure, it will be possible to see, for which ratios of size, a milling strategy is efficient or not.
\end{abstract}

\section{INTRODUCTION}

The importance of the cavity machining in the industry is reflected in many research works. The research lines are mainly about a fine understanding of the cutting phenomena [1], the improvement of tools [2], the cutting conditions optimization [3], the tool path geometry [4], the tool(s) choices [5], the milling time modeling [6, 7].

The most mechanical cavities are 2D1/2 i.e. with their wall perpendicular to the XY plane, so they can be milled, on a 3 -axis machine. The milling process is often decomposed in three phases: roughing, semi-finishing and finishing. During the roughing phase, a maximum material removal rate must be reached, taking constraints into account (spindle power, axis speed and acceleration, vibrations, ...).

For milling a 2D1/2 pocket, the toolpaths come, most of time, from a Computer Aided Manufacturing (= CAM) software who proposed classical tool trajectories as "zig-zag" or "contour parallel". Because of tangency discontinuity (or local high curvature) of the trajectory but also stop and go of the tool, these toolpaths are, fundamentally, not efficient in High Speed Milling (HSM). Aware of this kind of problems, some authors [8] and software designers modify locally the toolpath to improve his efficiency in HSM. From another hand, M. Bieterman and D. Sandström [9] have proposed a method to generate a globally HSM efficient toolpath (ie. a $\mathrm{C}^{2}$ spiral with low curvature). 
The goal of this paper is to characterize the time performance of four different machining strategies, for pocket roughing (zig-zag, contour parallel, morph spiral and Bieterman), using a software developed in the LURPA Lab from Cachan and called VPOp [10].

\section{DETAILED PRESENTATION}

\section{The pockets and the tools}

In order to study the impact of the pocket size on the choice of a toolpath, a simple geometry pocket is chosen: a rectangle of $200 \mathrm{~mm}$ per $120 \mathrm{~mm}$ with 4 fillets of $20 \mathrm{~mm}$ radius (cf. Fig.1). Such cavities are often used in the aerospace field and serve to contain and fix electronic components. This pocket is machined with a cylindrical tool of $10 \mathrm{~mm}$ diameter engaged at $75 \%$. A homothetic factor, called $k$, is applied on the various dimensions of the pocket to create a set of various pockets. The different pockets will be called by their $k$ factor. The same homothetic factor is applied to the tool size.

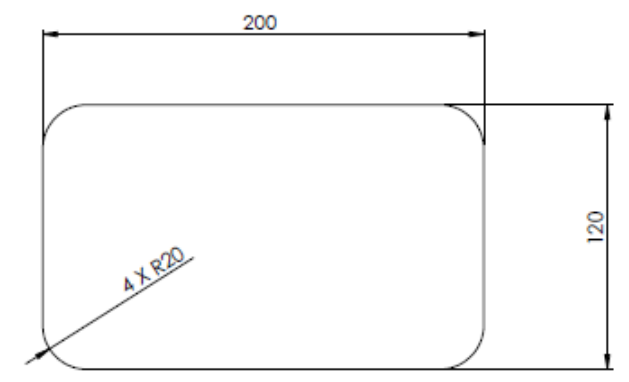

FIGURE 1. Geometry and dimension of the reference pocket

\section{The VPOp software}

In HSM, the actual feedrate is limited by the velocity, acceleration and jerk of each axis of the machine tool. The VPOp (Velocity Profile Optimization) algorithm aims at finding an optimized feedrate profile which makes the best use of the kinematical characteristics of the machine. This is achieved by intersecting all the constraints given by the axes in an iterative algorithm. The milling time is estimated through the feedrate profile [10].

\section{The modelized milling center}

VPOp uses a model of the MIKRON UCP710 milling center (5-axis). The acceleration of X and Y axis are 2.5 and $3 \mathrm{~m} / \mathrm{s}^{2}$ respectively. The programmed feedrate $\left(V_{f}\right)$ is $10000 \mathrm{~mm} / \mathrm{min}$.

\section{The classical toolpths}

The toolpaths referenced in this point are generated by the software Mastercam $\mathrm{X} 2^{\circledR}$.

$$
\text { Zig-zag }
$$

Also known as direction parallel milling, this toolpath is detailed by M. Held [11]. The tool covers the pocket by following lines parallel to a given reference direction (Fig. 2 (a) ). This method is relatively easy to encode but creates a lot of "stop and go" for the tool. Note that this trajectory leaves non-machined zones (red arrows on the figure); to mill the same volume as other trajectories, an offset toolpath should be added. 


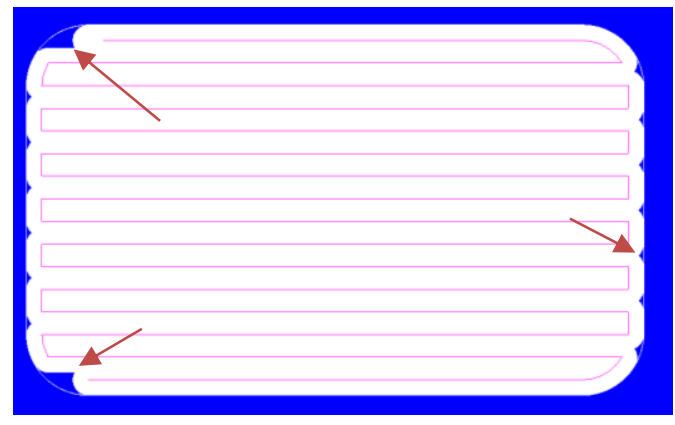

(a)

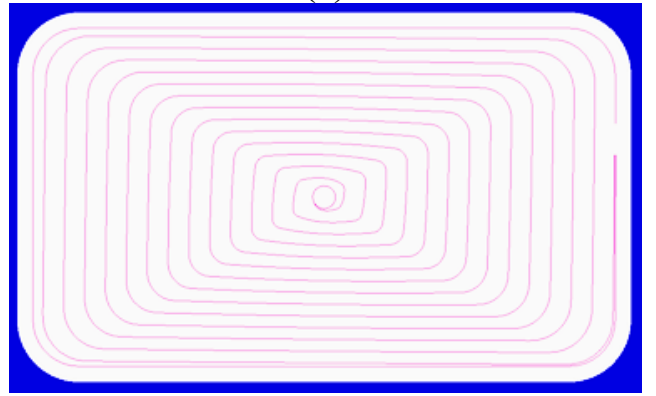

(c)

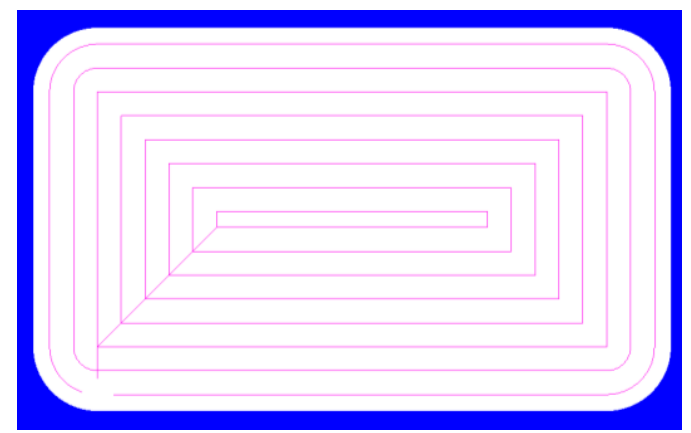

(b)

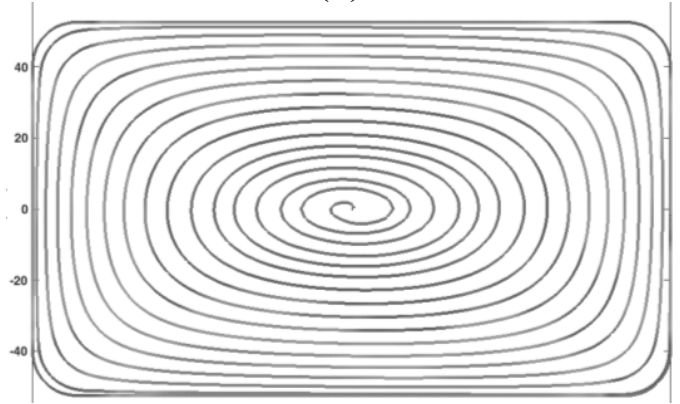

(d)

FIGURE 2. Zig-zag (a), contour parallel (b), morph spiral and Bieterman toolpaths applied to the rectangular pocket.

\section{Contour Parallel}

The trajectories elements are parallel to the pocket borders (offset curves). The tool travels from inward to outward (Fig. 2 (b)). The first difficulty of this method is to find the offset curves. H. Persson [12] proposed a method who was generalized by M. Held [13, 14] with the use of Voronoï diagrams. This category of toolpaths creates also tangency discontinuities who lead to a decrease of the average feedrate of the tool. Note that with this toolpath, all the pocket is directly machined.

\section{Morph spiral}

This trajectory is built like a spiral. There is therefore no stop and restart of the tool, as on conventional trajectories. However, we observe that the toolpath quickly takes the appearance of the border's pocket. Continuity in tangency seems guaranteed (no feedrate jump) but not the continuity in curvature (acceleration jumps) (Fig. 2 (c) ).

\section{The Bieterman and Sandström 's toolpath}

The Bieterman and Sandström's trajectory, detailed below, offers a double advantage: $\mathrm{C}^{2}$ continuity (no feedrate and no acceleration jumps) and a spiral shape who progressively morph to the border's pocket. So, the local curvature remains low and the toolpath can be followed at high speed [9].

\section{Principle}

This spiral path is obtained by interpolation between structure curves which are solutions of an elliptic partial differential equation (PDE). M. Bieterman and D. Sandström use Poisson's equation as PDE. Once the trajectory obtained, the feedrate is optimized with the use of a two-pass algorithm. 


\section{Implementation of the Bieterman and Sandström method}

Solving the Poisson's equation $(-\Delta u(x, y)=1)$ for a closed surface amount to research the stationary temperature field $(T(x, y)$ in $[\mathrm{K}])$ of this uniformly warmed surface and maintain at $0[\mathrm{~K}]$ on the borders (Eq. 1). The thermal conductivity of the material is $\lambda([\mathrm{W} / \mathrm{K}])$ and the thermal power areal density is $q\left(\left[\mathrm{~W} / \mathrm{m}^{2}\right]\right)$.

$$
\rho . c \cdot \frac{\partial T}{\partial \tau}=\vec{\nabla}(\lambda \cdot \vec{\nabla} T)+q \stackrel{\text { Steady State }}{=}-\Delta T=\frac{q}{\lambda}, \partial \Omega=0
$$

Thanks to this physical model, Solidworks ${ }^{\circledR}$ and his finite elements module can be used for drawing and offsetting the pocket and also for researching the temperature field [15]. The geometry and the results are afterwards imported to MATLAB ${ }^{\circledR}$ for the toolpath determination. This method directly gives a start point to the spiral: the point where the temperature is maximum. Then, the spiral is built by a blending work on isotherms. The selected ones are those for which the maximum radial distance is equal to the tool diameter corrected with a safety factor (=stepover). Then, a linear interpolation is realized between these isotherm curves (Eq. 2). Let $\rho_{s}(\theta)$ the polar equation of the spiral arc between two isotherms ( $\theta$ belongs to $\left[0,2 \pi[), \rho_{e}(\theta)\right.$ and $\rho_{i}(\theta)$ the polar equation of the external and internal isotherms respectively. Figure 1(d) gives an example of so build Bieterman's toolpath.

$$
\rho_{S}(\theta)=\rho_{i}(\theta)+\left(\rho_{e}(\theta)-\rho_{i}(\theta)\right) * \frac{\theta}{2 \pi}
$$

\section{Efficiency indicators}

Two indicators have been chosen to compare the different toolpaths: the simulated milling times (noted $\mathrm{t}_{\mathrm{zz}}, \mathrm{t}_{\mathrm{cp}}, \mathrm{t}_{\mathrm{ms}}$, $t_{\text {biet }}$ for zig-zag, contour parallel, morph spiral and Bieterman toolpaths) and the quotient (used as efficiency indicator and noted eff) between the theoretical milling time $\left(t_{t h}\right)$ and the simulated one (Eq. 3,4$) \cdot \bar{V}$ is the average speed along the toolpath.

$$
\begin{aligned}
& t_{t h}=\frac{\text { toolpath }^{\prime} \text { s length }}{\text { programmed feedrate }}=\frac{L}{V_{f}} \\
& \text { eff }=\frac{t_{t h}}{t_{z z / c p / m s / b i e t}}=\frac{\bar{Z}_{z z / c p / m s / b i e t}}{V_{f}}
\end{aligned}
$$

\section{EXPERIMENTAL PROCEDURE}

A series of homothetic pockets has been generated. The tool used to mill the pocket suffers the same homothetic factor. Mastercam $\mathrm{X} 2 \AA$ is then used to create zig-zag, contour parallel and morph spiral toolpaths. Gcode files are also created by Mastercam. The Gcode toolpaths are transformed in point to point toolpaths with Matlab who will be

\begin{tabular}{|c|c|}
\hline $\begin{array}{c}\text { Mastercam } \\
\text { (toolpath generation) }\end{array}$ & $\begin{array}{c}\text { VPOp } \\
\text { (milling time estimation) }\end{array}$ \\
\hline $\begin{array}{c}\text { Cylindrical tool } \\
\text { Diameter: } 10 * \mathrm{k} \\
\text { Stepover: } 75 \% \\
\text { Only roughing, no finishing path }\end{array}$ & $\begin{array}{c}\text { B-spline interpolation } \\
\text { Programmed feedrate: } 10000 \\
\mathrm{~mm} / \mathrm{min} \\
\text { Autorized jerk overrun: } 120 \% \\
\text { Acceleration: } 10 \mathrm{~m} / \mathrm{s}^{2} \\
\text { Jerk: } 5 \mathrm{~m} / \mathrm{s}^{3}\end{array}$ \\
\hline
\end{tabular}
used in VPOp to estimate the milling time. The Bieterman's toolpath is directly injected in VPOp. The table 1 details the most relevant input parameters.

TABLE 1. Most relevant parameters used in softwares. 


\section{RESULTS}

The simulated milling times and the efficiency indicator (eff) for each value of $k$ and for the different toolpaths are synthetized in the table 2 . The figures 3 and 3 show this results in graphics.

TABLE 2. Simulated milling times and efficiency indicators for different toolpaths

\begin{tabular}{ccccccccc}
\hline $\mathbf{k}$ & $\mathbf{t}_{\mathbf{z z}}(\mathbf{s})$ & $\mathbf{t}_{\mathbf{c p}} \mathbf{( s )}$ & $\mathbf{t}_{\mathbf{m s}} \mathbf{( s )}$ & $\mathbf{t}_{\text {biet }}(\mathbf{s})$ & eff $_{\mathbf{z z}}$ & eff $_{\mathbf{c p}}$ & eff $_{\mathbf{m s}}$ & eff $_{\text {biet }}$ \\
\hline 0.2 & 16 & 22,5 & 27,5 & 19 & 0,23 & 0,17 & 0,20 & 0,34 \\
0.4 & 19 & 26 & 35 & 24 & 0,39 & 0,29 & 0,31 & 0,53 \\
0.6 & 23 & 30 & 40 & 29 & 0,48 & 0,38 & 0,41 & 0,66 \\
0.8 & 27,5 & 33 & 46 & 34 & 0,54 & 0,46 & 0,48 & 0,75 \\
1.0 & 33 & 39 & 51 & 39 & 0,57 & 0,48 & 0,54 & 0,82 \\
1.2 & 35 & 41 & 55 & 45 & 0,64 & 0,55 & 0,60 & 0,85 \\
1.4 & 37,5 & 44 & 59 & 50 & 0,69 & 0,60 & 0,65 & 0,89 \\
1.6 & 41 & 46 & 63 & 56 & 0,72 & 0,66 & 0,70 & 0,91 \\
\hline
\end{tabular}

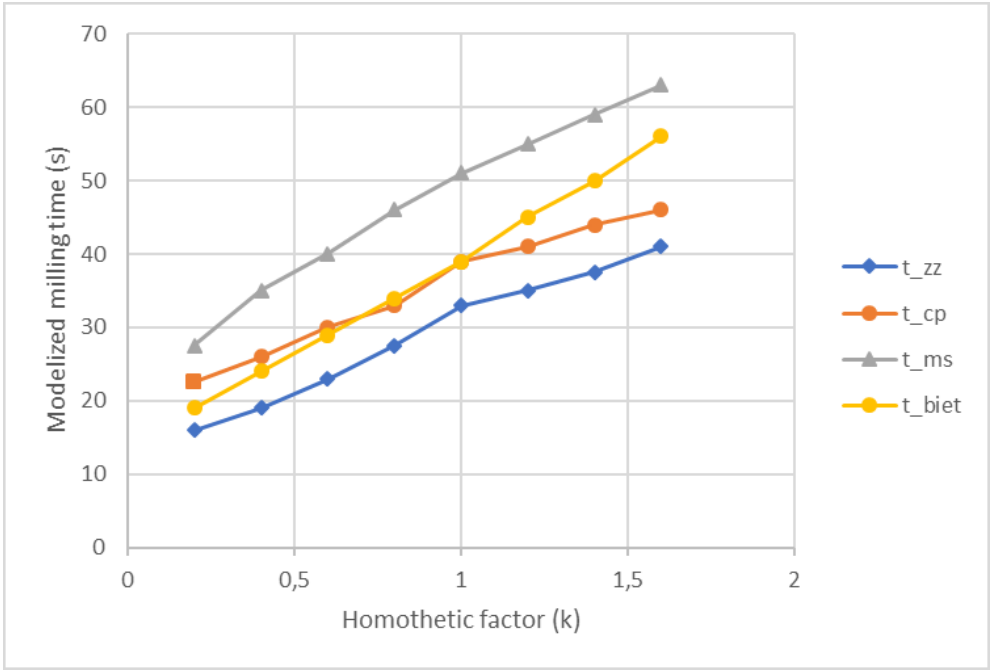

FIGURE 3. Simulated milling time for different toolpaths

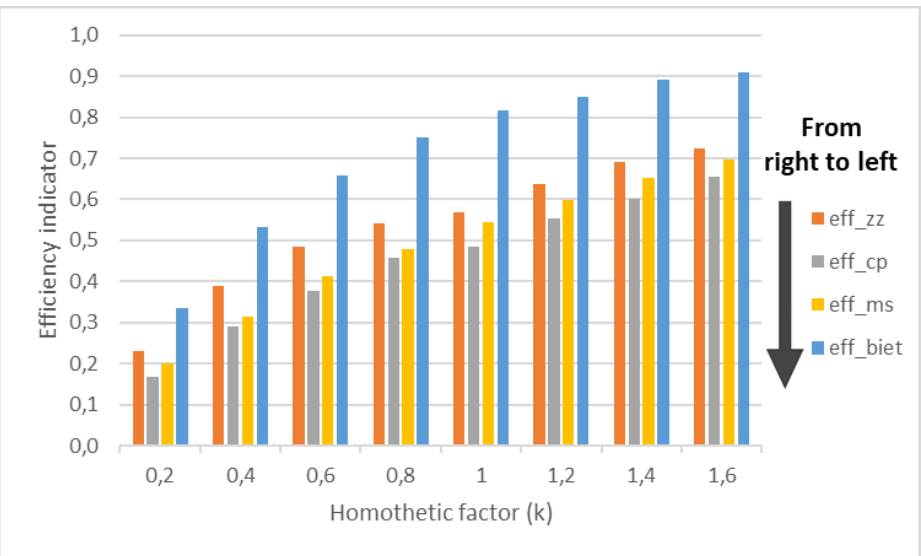

FIGURE 4. Efficiency indicators for different toolpaths 


\section{CONCLUSIONS AND PROSPECTS}

These simulations prove an intuition: when the cavities are small, the kinematic performance of the machine is very important and Bieterman's toolpaths, even if they are longer than the conventional trajectories, are temporally efficient. This is less the case for larger cavities. Furthermore, this article offers a procedure for quantifying the type of temporally efficient trajectories, given a cavity, a tool and a machine.

Simulations show also that the efficiency indicator is always the best for Bieterman's spiral, which proves that this geometry of trajectory allows the feedrate to remain close to the programmed one. It should also be noted that spiral trajectories respect more the machine tool and increase the lifetime of the tools.

\section{ACKNOWLEDGMENTS}

We wish to thank the LURPA lab from ENS Paris-Saclay for the VPOp licencing agreement, X. Beudaert for the developed software and S. Lavernhe for the collaboration proposition and the parameterization of the software.

\section{REFERENCES}

[1] P.J. Arrazola and al. (2013), Recent advances in modelling of metal machining processes, CIRP Annals Manufacturing Technology 62, $695-718$.

[2] V. A. Rogov and al. (2017), Improvement of cutting tool performance during machining process by using different shim, archives of civil and mechanical engineering 17, $694-710$.

[3] S. Aggarwal, P. Xirouchakis (2013), Selection of optimal cutting conditionsfor pocket milling using genetic algorithm, Int. J. Adv. Man. Technol. 66, 1943-1958.

[4] M. Bouard et al. (2011), Pocketing toolpath computation using an optimization method, Computer-Aided Design 43, 1099 - 1109.

[5] Z. Ahmad, K. Rahmani, R. D’Souza (2010), Applications of genetic algorithms in process planning: tool sequence selection for 2.5-axis pocket machining, J Intell Manuf 21, 461 - 470.

[6] J. Dong, J. A. Stori (2007), Optimal feed-rate scheduling for high-speed contouring, Journal of manufacturing science and engineering 129, $63-76$.

[7] X. Beudaert, S. Lavernhe, Ch. Tournier (2012), Feedrate interpolation with axis jerk constraints on 5-axis NURBS and G1 tool path, International Journal of Machine Tools and Manufacture 57, 73 - 82.

[8] V. Pateloup, E. Duc, P. Ray (2004), Corner optimization for pocket machining, International Journal of Machine Tools and Manufacture 44, $1343-1353$.

[9] M. Bieterman, D. Sandström (2003), A curvilinear tool-path method for pocket machining. Journal of Manufacturing Science and Engineering, Transactions of the ASME 125/4, 709 - 715.

[10] X. Beudaert (2013), Commande numérique ouverte: interpolation optimisée pour l'usinage 5 axes grande vitesse des surfaces complexes, Ph.D. thesis, Ecole Normale supérieure de Cachan.

[11] M. Held, On the Computational Geometry of Pocket Machining, Springer Verlag, 1991.

[12] H. Persson (1978), NC machining of arbitrarily shaped pockets, Computer-Aided Design, Volume 10/3, 169 174.

[13] M; Held, G. Lukacs, L. Andor (1994), Pocket machining based on contour-parallel tool paths generated by means of proximity maps, Computer-Aided Design 26, $189-203$.

[14] M. Held (1998), Voronoï diagrams and offset curves of curvilinear polygons, Computer-Aided Design 30/4, $287-300$.

[15] C. Leroy, E. Rivière-Lorphèvre, E. Filippi (2014), Trajectoires curvilinéaires pour l'usinage de cavités avec îlot : une première approche, $8^{\text {eme }}$ assises Machines et Usinage Grande Vitesse. 